\title{
Roles of Kermanshahi Oil, Animal Fat, Dietary and Non- Dietary Vitamin D and other Nutrients in Increased Risk of Premenopausal Breast Cancer: A Case Control Study in Kermanshah, Iran
}

\author{
Asadollah Salarabadi ${ }^{1}$, Sepideh Arbabi Bidgoli ${ }^{2 *}$, Sayed Hamid Madani ${ }^{3}$
}

\begin{abstract}
Background: Kermanshahi oil is one the most favorable oils in Iran especially in Kermanshah province. We aimed to evaluate the role of usual intake of Kermanshahi oil and other kinds of dietary fats as well as different meats, vegetables and fruits, carbohydrates, cereals, grains, sweets, candy and lifestyle habits in risk of breast cancer. Materials and Methods: A case-control study with 47 consecutive, newly diagnosed premenopausal breastcancer patients and 105 age and socioeconomic matched healthy women was conducted from 2013-2014 in Imam Reza hospital of Kermanshah using a standardized, validated questionnaire assessing various anthropometric, socio-demographic, lifestyle and dietary characteristics. Results: Kermanshahi oil intake was associated with a 2.1-fold (OR= 2.123, 95\% CI 1.332- 3.38) $(\mathrm{p}=\mathbf{0 . 0 0 2})$ higher likelihood of having breast cancer, while daily intake of other solid animal fats also increased the likelihood by 2.8 -fold $(O R=2.754,95 \%$ CI 1.43- 5.273) $(p<0.001)$, after various adjustments made. Lack of fish oil, white meat, vegetables, soy products, nuts and dairy products (especially during adolescence) in daily regimens and lack of sun exposure were significantly associated with premenopausal breast cancer risk in this region. Conclusions: This study suggested that animal fat increases the risk of premenopausal breast cancer but many other dietary and non-dietary factors including calcium and vitamin D deficiency are consistently associated with increased odds of breast cancer in this region.
\end{abstract}

Keywords: Animal oil - vitamin D - nutrients - breast cancer - Iran

Asian Pac J Cancer Prev, 16 (17), 7473-7478

\section{Introduction}

Breast cancer is the most common malignancy among women worldwide (Anderson et al., 2008) which has been considered as the fifth cause of cancer related death both in the less developed (LDCs) and more developed (MDCs) countries (Ghiasvand et al., 2014). Out of LDCs countries, the breast cancer problem seems more serious in Iran because it affects Iranian women at least one decade younger than their counterparts in MDCs countries (Naderimagham et al., 2014) therefore there is an urgent need for detecting the underlying risk factors of premenopausal breast cancer and making appropriate policies to prevent this cancer in Iran and neighboring countries with similar etiologies.

Several studies have been focused on the reasons of early incidence of breast cancer in premenopausal Iranian women in comparison to postmenopausal ones and the underlying roles of hormonal and environmental factors have been described for the first time by us (Bidgoli et al.,
2010). Later the specific roles of PAHs, xenoestrogens, obesity (Bidgoli et al., 2011) and vitamin D deficiency (Bidgoli et al., 2014) on increased risk of premenopausal breast cancer was emphasized through dietary and environmental resources (Ataollahi et al., 2014) but there are still knowledge gaps regarding the roles of diet, adiposity and BMI in early life, at menarche and at lifetime period on increased risk of premenopausal breast cancer (Rosner et al., 2015) which may not support the hypothesis about the long term adult weight gain and increased risk of breast cancer like postmenopausal women (Suzuki et al., 2013).

The environmental exposures, especially dietary habits, have been reported as the cause of $70 \%$ of sporadic breast cancers but the role of a high-fat diet as a risk factor for breast cancer has been remained controversial (Mourouti et al., 2014). Animal experiments, ecology studies and case-control studies have all shown that a high-fat diet is a risk factor for breast cancer; however according to the cohort studies in human population, the

${ }^{1}$ Pharmaceutical Sciences Research Center, ${ }^{2}$ Department of Toxicology and Pharmacology, Faculty of Pharmacy, Islamic Azad University, Pharmaceutical Sciences Branch (IAUPS), ${ }^{3}$ Department of Pathology, Faculty of Medicine, Kermanshah University of Medical Sciences, Kermanshah, Iran Iran*For correspondence: sepideharbabi@yahoo.com 
result is still controversial. (Wu et al., 2015).

The contribution of Iranian dietary habits on breast cancer risk has been described recently by focusing on the roles of increased consumption of fats and high-fat meats (Mobarakeh et al., 2014). Using animal fats and oils derived from animals is a flavored dietary habit in Iranian population especially in Kermanshah province where the Kermanshahi animal oil has been traditionally produced in more than 600 tons annually by Tribes and Villagers there (Najafi et al., 2011), but there is no study to evaluate the effects of Kermanshai animal fat, other fat sources and their levels as well as the other dietary habits in premenopausal breast cancer patients in comparison to age matched healthy women. Present study aimed to determine the effect of fat consumption and other dietary resources on breast cancer in women who had born and lived continuously in Kermanshah-Iran.

\section{Materials and Methods}

\section{Population study}

A case-control study was conducted on 47 newly diagnosed premenopausal breast cancer patients and 105 normal healthy women as control group. Both evaluated groups lived in Kermanshah and surrounding villages in Kermanshah Province, the largest Province in the western part of Iran which is neighbor to Iraq. We selected cases from patients who underwent surgery from 2012 to 2014 in Imam Reza University hospital which has a pathologybased cancer registry system. Cases were identified from both self-reports registration and confirmed by pathological reports. The pathological feature of cases was collected from pathological reports in the pathology archive of the mentioned hospital and all were diagnosed with invasive ductal carcinoma.

Upon approval from Ethics Committee of Kermanshah University of Medical Sciences and for the purpose of this study, all positive pathologic reports for a breast cancer from 2012 to 2014 were included. For every year that the data were available in the provincial registry, the registered cases were compared with pathologic reports and in case of a mismatch, the new cases were included. Data were then sorted by name, father's name and age.

\section{Exclusion criteria}

Patients women with familial history of breast cancer were excluded from present study. According to the addresses which were provided in pathology reports, the referred cases from neighboring provinces were excluded. Exclusion criteria for cases and controls were menopausal evidence, any evidence of pregnancy, recent lactation and history of malignancy. Menopausal status at the time of recruitment was defined according to information on ovariectomy, hysterectomy, menstruation status (still menstruating, number of menses over the past 12 months). Women were considered postmenopausal if they had undergone a bilateral ovariectomy or if their menses had stopped 12 months or more (unless due to hysterectomy) ago. Women who were still menstruating by using exogenous hormones and women with no information on the number of menses over the past 12 months were excluded from this study. The control group was matched with cases for age \pm 5 years. Cases and controls were selected from people who didn't expose to PAHs producing manufactures as well as X-ray resources according to their living and working addresses.

\section{Questionnaires}

All information was collected by expert nurses according to standardized questionnaires/protocols that have been previously developed and successfully used by us (Bidgoli SA, 2014) .Other than demographic data, body measurements including weight, height, and calculated body mass index, occupation, physical activity (time spent in mild, moderate, and vigorous activities), daily exposure to sunlight and all details regarding body coverage, daily intake of calcium and vitamin D and all dietary resources were collected. The dietary resources were categorized as below according to the KIDMED test (Castro-Quezada et al., 2014)

Dietary fats: According to preliminary questions and local dietary habits dietary, fats were categorized to Kermanshahi animal oil, Solid animal oil, Plant derived oil, Butter /Margarin and Fish oil /omega 3.

Dairy products: According to preliminary questions and local dietary habits daily drinking of milk, Yoghurt, Chesses and pattern of dairy consumption in adolescence were asked. All volunteers were asked whether they has a dairy product for breakfast (yoghurt, milk, etc), if they takes two yoghurts and/or some cheese (40 g) daily and whether they use calcium or vitamin D supplementary pills daily.

Meat, Soy products and Egg :All volunteers were asked if the consume meat regularly a and how often they consume red meat, white meat, fish, fast food( hamburger) and fish, soy products and egg in their routine dietary regimens.

\section{Vegetables and fruits}

Every volunteer was asked if she takes a fruit or fruit juice every day, if she has a second fruit every day and if she takes fresh or cooked vegetables regularly once or more than once a day.

\section{Carbohydrates, cereals, grains, sweets and candy:}

They asked if they Consume pasta or rice almost every day ( 5 or more per week) and if they have cereals or grains (bread, etc) for breakfast and if they take sweets and candy several times every day.

Others: Consumption of nuts, green tea and olive regularly (at least 2-3/week) were also recorded.

\section{Statistical analyses}

Values were expressed as percent per population or as the mean \pm standard deviation (SD) .To assess the association between clinicopathological data, student ttest or nonparametric chi-square test was used. Relative risks and Odds ratios were calculated by Cochran's and Mantel Haenszel statistics using SPSS 21.Probability values of $<0.05$ and Odds ratios $>1$ were considered significant. 


\section{Results}

Anthropometric and background factors:

In this age and socioeconomics matched case control study, demographic, anthropometrics, history of background factors and lifestyle factors were compared at first(data were not showed). Out of different compared variables no significant differences were considered in weight, height, BMI, weight at menstruation, weight at $18 \mathrm{yrs}$, weight at delivery, weight after delivery, highest weight at lifetime period and trends of weight changes after delivery of cases in comparison to control group. The incidence of background diseases were not significantly different between two groups too.

Out of different lifestyle factors, increased body coverage against sunlight exposure $(\mathrm{p}=0.004$, $\mathrm{OR}=2.868,95 \% \mathrm{CI} 1.215-6.768)$, lack of physical activity $(\mathrm{p}=0.043, \mathrm{OR}=1.975,95 \% \mathrm{CI} 0.97-4.03)$ and continuous $(>5 \mathrm{yrs})$ OCP consumption $(\mathrm{p}=0.003, \mathrm{OR}=3.1$, $95 \% \mathrm{CI}=1.32-7.29)$ were considered as three important risk factors of premenopausal breast cancer in this case and control study in Kermanshah like our previous studies in other provinces of Tehran (Bidgoli SA, 2011) (Bidgoli SA, 2014).

\section{Dietary habits}

Fat consumption: Dietary fats were categorized to 4 groups Kermanshahi animal oil, animal oil, liquid oil and butter/Margarine. Table 1 compares the consumption levels of routine dietary oils between cases and control group. Out of four different routine dietary oils, higher prevalence of animal oils was detected in cases when compared with control $(80.85 \%$ vs $51.42 \%, \mathrm{p}<0.001, \mathrm{OR}=2.75,95 \% \mathrm{CI} 1.44-5.27)$. As the last important finding was the significant lower levels of fish oil consumption in breast cancer patients $(2.13 \% \mathrm{vs}$ $12.38, \mathrm{p}=0.034, \mathrm{OR}=6.5,95 \% \mathrm{CI} 0.82-51.23$ ).

\section{Dairy Products, Calcium and vitamin D supplements}

Dietary dairies were categorized to 4 groups according to the nutritional habits of women in Kermanshah. Table 2 compares the consumption levels of routine dietary dairies between cases and control group as well as their habits in adolescence. Out of four different routine dietary dairies, breast cancer patients showed lower levels of milk consumption $(36.17 \%$ vs $55.24 \%, \mathrm{p}=0.023$, $\mathrm{OR}=2.18,95 \% \mathrm{CI} 1.07-4.42$ ) and lower levels of yogurt consumption $(76.6 \%$ vs $93.33 \%, \mathrm{p}=0.005, \mathrm{OR}=4.28,95 \% \mathrm{CI}$ 1.54-11.89) were detected in cases when compared with control. Interestingly cases showed lower levels of dairy

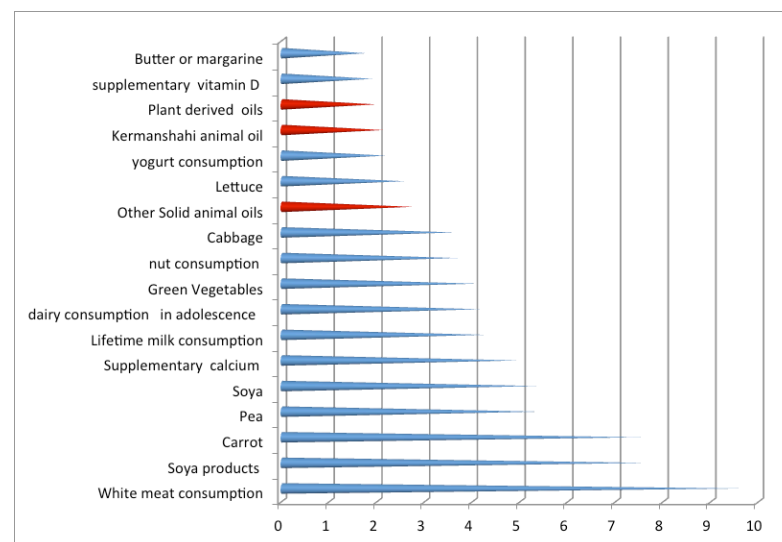

Figure 1. Pattern of Milk Consumption in Adolescence

Table 1. Comparison of the Consumption Levels of Routine Dietary Oils between Cases and Control Group

\begin{tabular}{|c|c|c|c|c|c|}
\hline Characteristics & Breast Cancer $=47(\mathrm{~N} \%)$ & Control $=105(\mathrm{~N} \%)$ & P-Value & OR & $\mathrm{CI}(95 \%)$ \\
\hline Kermanshahi animal oil(+) & $25(53.19)$ & $28(26.67)$ & 0.002 & 2.2 & $1.33-3.38$ \\
\hline Kermanshahi animal oil(-) & $22(46.81)$ & $77(73.33)$ & & & \\
\hline Other Solid animal oils(+) & $38(80.85)$ & $73(69.52)$ & $<0.001 *$ & 2.75 & $1.448-5.27$ \\
\hline Other Solid animal oils(-) & $9(19.15)$ & $32(30.48)$ & & & \\
\hline Plant derived oils(+) & $40(85.11)$ & $73(69.52)$ & $0.031^{*}$ & 1.97 & $0.96-4.03$ \\
\hline Plant derived oils(+) & $7(14.89)$ & $32(30.48)$ & & & \\
\hline Butter or margarine $(+)$ & $15(31.91)$ & $17(16.19)$ & $0.026^{*}$ & 1.75 & $1.09-2.82$ \\
\hline Butter or margarine(-) & $32(68.09)$ & $88(83.81)$ & & & \\
\hline Fish oil /Omega3(+) & $1(2.13)$ & $13(12.38)$ & $0.034 *$ & 6.5 & $0.82-51.23$ \\
\hline Fish oil /Omega3(-) & $46(97.87)$ & $92(87.62)$ & & & \\
\hline
\end{tabular}

Table 2. Comparison of the Consumption Levels of Routine Dietary Dairies, Calcium and Vit D Supplements between Cases and Control Group

\begin{tabular}{|c|c|c|c|c|c|}
\hline Characteristics & Cancer $=47(\mathrm{~N} \%)$ & Control= $105(\mathrm{~N} \%)$ & P-Value & OR & $\mathrm{CI}(95 \%)$ \\
\hline Daily drinking of milk (+) & $17(36.17)$ & $58(55.24)$ & & & \\
\hline Daily drinking of milk (-) & $30(63.83)$ & $47(44.76)$ & $0.023 *$ & 2.18 & $1.07-4.42$ \\
\hline Yoghurt(+) & $36(76.60)$ & $98(93.33)$ & & & \\
\hline Yoghurt(-) & $11(23.40)$ & $7(6.67)$ & $0.005^{*}$ & 4.28 & $1.54-11.89$ \\
\hline Cheese (+) & $38(80.85)$ & $92(87.62)$ & & & \\
\hline Cheese (+) & $9(19.15)$ & $13(12.38)$ & 0.273 & 1.6 & $0.66-4.25$ \\
\hline Pattern of dairy consumption in adolescence (Daily) & $3(15.79)$ & $29(43.94)$ & & & \\
\hline Pattern of dairy consumption in adolescence (weekly) & $16(84.21)$ & $37(56.06)$ & $0.022 *$ & $4.18^{*}$ & $1.11-1573$ \\
\hline Supplementary calcium (+) & $2(4.25)$ & $19(18.10)$ & & & \\
\hline Supplementary calcium (-) & $45(95.75)$ & $86(81.90)$ & $0.016^{*}$ & $4.97 *$ & $1.11-22.3$ \\
\hline Supplementary vitamin $\mathrm{D}(+)$ & $3(6.38)$ & $12(11.43)$ & & & \\
\hline Supplementary vitamin D(-) & $44(93.62)$ & $93(88.57)$ & 0.335 & 1.89 & $0.51-7.05$ \\
\hline
\end{tabular}


Table 3. Comparison of the Consumption Levels of Different Meats, Soy Products and Egg between Cases and Control Group

\begin{tabular}{|c|c|c|c|c|c|c|}
\hline & & Breast cancer & Control & p-value & OR & $\mathrm{CI}(95 \%)$ \\
\hline \multicolumn{7}{|c|}{ Characteristics } \\
\hline & Read meat(Daily) & $2(4.3)$ & $16(15.2)$ & 0.83 & NS & \\
\hline & Read meat Weekly & $28(59.6)$ & $59(56.2)$ & & & \\
\hline & Read meat Monthly & $13(27.6)$ & $27(25.7)$ & & & \\
\hline & NO Read meat & $4(8.5)$ & $3(2.9)$ & & & \\
\hline \multicolumn{7}{|c|}{ Fish(Weekly) } \\
\hline & Yes & $29(61.70)$ & $80(76.20)$ & 0.052 & 1.99 & $0.95-4.16$ \\
\hline & No & $18(38.30)$ & $25(23.80)$ & & & \\
\hline \multicolumn{7}{|c|}{ White meat } \\
\hline & Daily & $8(17)$ & $49(46.6)$ & & & \\
\hline & Weekly & $35(74.5)$ & $55(52.4)$ & $<0.001 *$ & $9.674 *$ & $1.05-89.07$ \\
\hline & Monthly & $4(8.5)$ & $1(1)$ & & & \\
\hline \multirow[t]{2}{*}{ Egg } & $>3$ eggs /week & $38(80.85)$ & $68(64.76)$ & & & \\
\hline & $<3$ eggs /week & $9(19.15)$ & $37(35.24)$ & 0.033 & 1.832 & $0.97-3.47$ \\
\hline \multirow[t]{2}{*}{ Soya } & Yes & $12(25.53)$ & $68(64.76)$ & & & \\
\hline & No & $35(74.47)$ & $37(35.24)$ & $<0.001 *$ & $5.360 *$ & $2.49-11.56$ \\
\hline \multicolumn{7}{|c|}{ Soy products } \\
\hline & $1 / 4$ cup or more than $1 / 4$ cup at week & $3(6.38)$ & $36(34.29)$ & & & \\
\hline & 0 cup or Less than $1 / 4$ cup at week & $44(93.62)$ & $69(65.71)$ & $<0.001 *$ & $7.652 *$ & $2.221-26.364$ \\
\hline
\end{tabular}

Table 4. Comparison of the Consumption Levels of Different Vegetables between Cases and Control Group

\begin{tabular}{|c|c|c|c|c|c|c|}
\hline & & Breast cancer & Control & p-value & OR & $\mathrm{CI}(95 \%)$ \\
\hline \multirow[t]{2}{*}{$\overline{\text { Green Vegetables }}$} & Yes & $39(82.98)$ & $100(95.24)$ & & & \\
\hline & No & $8(17.02)$ & $5(4.76)$ & $0.012 *$ & $4.103 *$ & $1.264-13.312$ \\
\hline \multirow[t]{2}{*}{ Lettuce } & Yes & $37(78.72)$ & $95(90.48)$ & & & \\
\hline & No & $10(21.28)$ & $10(9.52)$ & $0.048 *$ & $2.568 *$ & $0.988-6.674$ \\
\hline \multirow[t]{2}{*}{ Cabbage } & Yes & 32 (68.09) & $93(88.57)$ & & & \\
\hline & No & $15(31.91)$ & $12(11.43)$ & $0.002 *$ & $3.633^{*}$ & $15.39-8.575$ \\
\hline \multirow[t]{2}{*}{ Carrot } & Yes & $29(61.70)$ & $97(92.38)$ & & & \\
\hline & No & $18(38.30)$ & $8(7.62)$ & $<0.001 *$ & $7.526 *$ & $2.968-19.082$ \\
\hline \multirow[t]{2}{*}{ Pea } & Yes & $23(48.94)$ & $88(83.81)$ & & & \\
\hline & No & $24(51.06)$ & 17 (16.19) & $<0.001 *$ & $5.402 *$ & $2.49-11.7$ \\
\hline
\end{tabular}

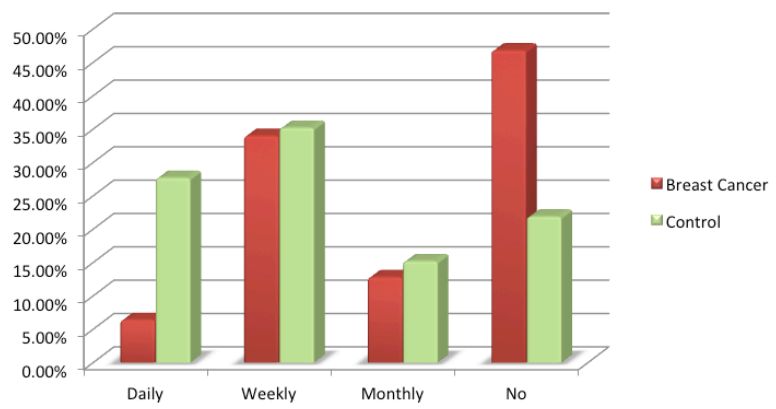

Figure 2. Ranking of Dietary Risk Factors (red) and Inhibitory Dietary Habits(blue) in Breast Cancer Patients according to the Odds Ratios

consumption in their adolescent period when compared with control $(15.79 \%$ vs $43.94 \%, \mathrm{p}=0.022, \mathrm{OR}=4.18$, 95\% CI 1.11-15.73). Figure 1 compares the pattern of drinking milk and in adolescence between cases and control group. In fact only $5 \%$ of patients were used to drink milk daily in that period. Calcium supplements were used in control group significantly higher than cases $(18.1 \%$ vs $4.25 \%, \mathrm{p}=0.016, \mathrm{OR}=4.97,95 \%$ CI $1.11-22.3)$.

Meat, Soy products and Egg

As we determined in table 3 , the significant protective roles of soy $(\mathrm{p}<0.001, \mathrm{OR}=5.36, \mathrm{CI}=2.49-11.56)$,soy products $(\mathrm{p}<0.001, \mathrm{OR}=7.65, \mathrm{OR}=2.22-26.36)$ and white meat $(\mathrm{p}<0.001, \mathrm{OR}=9.67,95 \% \mathrm{CI}=1.051-89.06)$ were recorded in this study.

Vegetables and fruits

The level of fruit consumption was compared between two groups and didn't show any significant difference (Data was not showed) but table 4 shows the significant differences in vegetable consumption between two groups.

Carbohydrates, cereals, grains, sweets and candy

The cases and control healthy group didn't show any significant difference in pasta, rice, bread, cereals, grains, sweets and candy consumptions. Healthy women used nuts more often than breast cancer patients $(71.43 \% \mathrm{vs}$ $40.42 \%, \mathrm{p}<0.001, \mathrm{OR}=3.68, \mathrm{OR}=1.79-7.57)$.

\section{Discussion}

Although the anthropometric variables were not significantly different between cases and healthy women, present study confirmed our preliminary hypothesis on the role of animal fats on increased risk of breast cancer. This study showed clearly how animal Kermanshahi oil consumption as well as the other animal fat resources may 
increase more than 2.7 folds the risk of premenopausal breast cancer in women who born and lived in. We have described the most important dietary habits of all volunteers in Table 1-4. Other than mentioned oils, fish oil consumption decreased the risk of breast cancer more than 6.5 times in healthy women which is in accordance to two previous meta- analysis studies in 2013 (Zheng et al., 2013) and 2014 (Yang et al., 2014) which has emphasized the crucial role of $n-3$ PUFA in prevention of breast cancer (Li et al., 2015).

The Mediterranean diet has been recently introduced as one of the healthiest dietary pattern worldwide which reduces the risk of certain pathologies, such as cancer or Cardiovascular Disease (Li et al., 2015) according to a meta-analysis study of randomized controlled trials (RCTs) in relevant articles regarding the Mediterranean diet and nutritional adequacy published from January 2000 to June 2013 (Castro-Quezada et al., 2014). As the Mediterranean diet could be used in public health nutrition policies in order to reduce micronutrient deficiencies and cancer risks, this template was considered in this study. Other than this guideline we matched this template by recording local dietary habits during adolescence and life time period in women who born and lived in Kermanshah. This age and socioeconomic matched case control study showed significant dietary protective factors which have been compared and ranked in figure 2 .

We have showed recently the role of vitamin D deficiency from dietary sources and lack of sun exposure on the incidence of premenopausal in Sabzevar of Iran (Bidgoli et al., 2014). Vitamin D is obtained from both dietary sources and exposure to sunlight (MF, 2007) and these two important ways were assessed at the same time in this study. Although similar to previous study, increased body coverage against sunlight exposure increased the breast cancer risk in Kermanshahi women $(\mathrm{p}=0.004, \mathrm{OR}=2.87,95 \% \mathrm{CI} 1.21-6.77)$, the dietary sources of vitamin D in cases and controls were not similar. Lack of white meat consumption increased 9.7 fold $(\mathrm{OR}=9.67,95 \% \mathrm{CI}, 1.05-89.07)$,soy, soy products and dairies especially milk consumption in adolescence and lifetime was significantly higher in normal women than cases.

Parallel to dietary fat restriction, closer attention should be paid to vitamin D deficiency in dietary, medical and pharmaceutical practice for women health. Due to updated knowledge on vitamin D from experimental, ecological, case-control, retrospective and prospective observational studies, meta-analysis as well as smaller intervention studies, the sunshine vitamin's essential role in a variety of physiological and preventative functions and the findings of this research are consistent with the recommendation to improve the general vitamin $\mathrm{D}$ status in children and adults by means of a healthy approach to sunlight exposure, consumption of vitamin D containing foods and supplements (Grober et al., 2015), (Scott et al., 2015).

One recent study on the role of dietary habits on breast cancer among middle-aged women in Greece showed adherence to healthy dietary patterns including whole grains, fruits, and vegetables, olive oil, and fish as a favorable regimen in breast cancer prevention (Mourouti et al., 2014). This study showed also clearly how vegetable intakes may differentially decrease the breast cancer risk 2.5 fold for lettuce, 3.63 fold for cabbage,5.4 fold for pea and 7.52 fold carrot in Iranian population. Overall, associations between breast cancer risk and consumption of red meat and poultry were of different magnitude in Asian African and Caucasian women, with further differences noted by menopausal and hormone receptor status in Caucasian women has been reported recently which had examined racial differences in meat and breast cancer risk and represents some of the first evidence in Asian American women (Chandran et al., 2013) which wasn't similar to our results in Iranian population.

In conclusion this study represents for the first time the role of calcium and vitamin D deficiency from dietary(meat and dairies) and non-dietary resources (lack of sun exposure), increase fat consumption and lack of vegetables, soy products and nuts in daily regimen of premenopausal women in Kermanshah which should be considered for cancer preventive strategies in the future.

\section{Acknowledgements}

Authors are thankful from Dr. Seyed Hamid Madani, Pathologist and the nurses and staff of Imam Reza University hospital as well as the administration of Kermanshah University of Medical Sciences for allowing the full access to the cancer registry archives during conducting this study.

\section{References}

Anderson BO, Jakesz R (2008). Breast cancer issues in developing countries: an overview of the Breast Health Global Initiative. World J Surg, 32, 2578-85.

Ataollahi M, Sedighi S, Masoumi SZ (2014). Nutritional and unhealthy behaviors in women with and without breast cancer. Iran Red Crescent Med J, 16, 19684.

Bidgoli SA, Ahmadi R, Zavarhei MD (2010). Role of hormonal and environmental factors on early incidence of breast cancer in Iran. Sci Total Environ, 408, 4056-61.

Bidgoli SA, Azarshab H (2014). Role of vitamin D deficiency and lack of sun exposure in the incidence of premenopausal breast cancer: a case control study in Sabzevar, Iran. Asian Pac J Cancer Prev, 15, 3391-6.

Bidgoli SA, Eftekhari T, Sadeghipour R (2011). Role of xenoestrogens and endogenous sources of estrogens on the occurrence of premenopausal breast cancer in Iran. Asian Pac J Cancer Prev, 12, 2435-30.

Castro-Quezada I, Román-Viñas B, Serra-Majem L (2014). The Mediterranean Diet and Nutritional Adequacy: A Review. Nutrients, 6, 231-48.

Chandran U, Zirpoli G, Ciupak G, et al (2013). Racial disparities in red meat and poultry intake and breast cancer risk. Cancer Causes Contro, 24, 2217-29.

Ghiasvand R, Adami HO, Harirchi I, et al (2014). Higher incidence of premenopausal breast cancer in less developed countries; myth or truth? BMC Cancer, 14, 1-8.

Gröber U, Reichrath J, Holick MF (2015). Live longer with vitamin d? Nutrients, 7, 1871-80.

Li D (2015) .Omega-3 polyunsaturated fatty acids and noncommunicable diseases: meta-analysis based systematic review. Asia Pac J Clin Nutr, 24, 10-5. 
Mobarakeh ZS, Mirzaei K, Hatmi N, et al (2014). Dietary habits contributing to breast cancer risk among Iranian women. Asian Pac J Cancer Prev, 15, 9543-7.

Mourouti N, Papavagelis C, Plytzanopoulou P (2015). Dietary patterns and breast cancer: a case-control study in women. J Nutr, 145, 2109-16.

Naderimagham S, Alipour S, Djalalinia S, et al (2014). National and sub-national burden of breast cancer in Iran; 1990-2013. Arch Iran Med, 17, 794-9.

Najafi T, Eghtesadi S,Rezaei M, et al (2011). The effect of Kermanshahi animal oil on serum lipid profile in healthy men. Behbood Journal, 14, 290-4.

Rosner B, Eliassen AH, Toriola AT, et al (2015). Short-term weight gain and breast cancer risk by hormone receptor classification among pre- and postmenopausal women. Breast Cancer Res Treat, 150, 643-53.

Scott MG, Gronowski AM, Reid IR, et al (2015). Vitamin D: the more we know, the less we know. Clin Chem, 61, 462-5.

Suzuki S, Kojima M, Tokudome S, et al (2013). Obesity/ weight gain and breast cancer risk: findings from the Japan collaborative cohort study for the evaluation of cancer risk. $J$ Epidemiol, 23, 139-45.

Wu YC, Zheng D, Sun JJ, et al (2015). Meta-analysis of studies on breast cancer risk and diet in Chinese women. Int J Clin Exp Med, 8, 73-85.

Yang B, Ren XL, Fu YQ, et al (2014). Ratio of n-3/n-6 PUFAs and risk of breast cancer: a meta-analysis of 274135 adult females from 11 independent prospective studies. $B M C$ Cancer, 14, 105.

Zheng JS, Hu XJ, Zhao YM, et al (2013). Intake of fish and marine n-3 polyunsaturated fatty acids and risk of breast cancer: meta-analysis of data from 21 independent prospective cohort studies. BMJ, 346, 3706. 